\title{
ROLE OF ANAESTHESIOLOGIST IN ULTRASOUND GUIDED REMOVAL OF VASCULAR TUMOR IN THE FOREARM
}

Gajendra Singh ${ }^{1}$, Pratima B. Patil ${ }^{2}$

\section{HOW TO CITE THIS ARTICLE:}

Gajendra Singh, Pratima B. Patil. "Role of Anesthesiologist in Ultrasound Guided Removal of Vascular Tumor in the Forearm". Journal of Evolution of Medical and Dental Sciences 2014; Vol. 3, Issue 65, November 27;

Page: $14235-14239$, DOI: $10.14260 /$ jemds/2014/3908

ABSTRACT: Re-exploration of a recurrent vascular tumor in a 20-year-old boy was done using ultrasound guided axillary nerve block. The tumor was operated one year back resulting in nonregression of the mass. He was re-operated after one year and the surgery was abandoned because of non-localization of the feeding vessel due to fibrosis and distorted anatomy. So the help of ultrasound guidance was sought by the surgeon to locate the feeding vessel. We helped the surgeons to ligate vessels by using high frequency ultrasound probe intraoperatively. Localization and confirmation of feeding vessels was done by using color flow mapping and Doppler study. This led to successful excision of the tumor with minimal bleeding. This case illustrates the invaluable contribution that usage of ultrasound by an anesthesiologist has made a very difficult and complex surgery into a very simple and easy one, resulting in successful outcome.

KEYWORDS: Anesthesiologist - Ultrasound - Nerve Block - Vascular Tumor - Doppler - color flow mapping.

INTRODUCTION: Ultrasound guided nerve blocks are becoming more and more popular due to their accuracy and improved success rate. In addition to locating the nerves for the block, in this case we have made use of ultrasound to locate the feeding vessels of the vascular tumor, which helped the surgeons to ligate the vessels very easily without much dissection.

BACKGROUND AND OBJECTIVES: Vascular tumors consisting of an afferent artery, arteriovenous canal, collagen, and efferent veins, and are most often located in the soft tissue of the upper extremities. We describe how the use of ultrasound guidance has helped the surgeon to locate the feeding vessels and ligation of the same with minimal dissection.

CASE HISTORY: A 20-year-old man was scheduled for excision of 1 year old vascular tumor over antero-medial aspect of the forearm. The tumor was operated one year back resulting in nonregression of the mass. He was re-operated in our own hospital, the surgery was abandoned because of non-localization of the feeding vessel due to fibrosis and distorted anatomy. So the help of ultrasound guidance was sought by the surgeon to locate the feeding vessel. Color Doppler imaging confirmed these pulsatile lesions to be vascular in origin.

Ultrasound-guided axillary blockade was the proposed anesthetic technique. A successful ultrasound-guided axillary brachial plexus blockade was performed uneventfully. It is not without reason that one can speak in this area of an individual nerve block rather than a plexus block. The axillary artery and the axillary vein, along with the fascia of the triceps arm muscle, served as anatomic landmarks.

Patient was premeditated with Midazolam 2mg and Fentanyl 100 mcg. 


\section{CASE REPORT}

Ultrasound guidance was used to visualize the 4 main nerves and then irrigate them with local anesthetic. The ultrasound-guided axillary block was carried out on short axes. The positioning of the arm was in abduction at $90^{\circ}$ in relation to the shoulder. The probe was set as near the axilla as possible perpendicular to the path of the nerves and vessels. On both sides of the (pulsing) artery the median nerve, lying cranial to it, and the ulnar nerve, lying caudally to it, was located. The radial nerve was located dorsal to the artery. The musculocutaneus nerve was localized in the area of the sheath between coracobrachialis and biceps muscles. The puncture was carried out by in-plane technique and each of the nerves was irrigated separately with $5-8 \mathrm{ml}$ of local anesthetic, $0.25 \%$ bupivacaine with $1 \%$ lignocaine with adrenaline. A total of $20 \mathrm{ml}$ of local anesthetic was used to block the 4 individual nerves.

The linear frequency USG probe was wrapped in a sterile glove and drape. The feeding vessel was localized after the area was painted and draped. It was situated at about $2 \mathrm{~cm}$ deep over the ulnar aspect of the mid forearm. This helped the surgeon to take the skin incision as near to the main feeding vessel as possible. Once the surgeon explored to some depth and crossed the subcutaneous plane, we located the vessel and directed the surgeon by keeping the tip of a needle just over the vessel. This helped in ligation of the vessel with minimum dissection.

Another vessel was similarly located $2 \mathrm{~cm}$ below the midpoint of the cubital fossa around $1.5 \mathrm{cms}$ deep. A third vessel was located posterior to the elbow which was around $2 \mathrm{cms}$ deep. This vessel had three to four feeding branches to the tumor. All these vessels were localized and confirmed by using color flow and Doppler study and they were ligated successfully. This caused shrinkage of the tumor. USG of the tumor showed decreased vascularity. This led to successful excision of the tumor with minimal bleeding.

DISCUSSION: Use of ultrasound in anesthesia is becoming more and more popular, especially in regional nerve blocks, advantage being the direct visualization of the nerves, avoiding inadvertent puncture of vessels and injury to other vital structures and helps in minimizing the volume of injected drug, thereby reducing side effects of local anesthetics. Numerous studies have been found where the help of sonologist has been sought to localize the position, extent and situation of feeding vessels in a vascular tumor, but they are all done preoperatively. To utilize the services of a sonologist intraoperatively is often not feasible.

Finn MC, Glowacki J, Mulliken JB, et al(1) have shown that History and physical examination results readily can be used to diagnose the majority of vascular birthmark.

Mulliken JB, Glowacki J,(2) concluded that vascular malformations are errors of morphogenesis and consists of abnormal channels lined by normal endothelium that has low turnover. These anomalies are sub classified according to predominant channel type - arterial, venous, capillary, lymphatic, or combination thereof by Mulliken and Glowacki in 1982. Vascular malformations are present at birth may not be evident until adolescent or adult life.

Enjolras 0, Mulliken $\mathrm{JB}^{(3)}$ showed that Radiologic evaluation is often required in two circumstances: (a) prior to institution of pharmacologic therapy for haemangioma to more precisely monitor therapeutic response and (b) before radiologic interventional treatment and/or resection of vascular malformations to accurately define their nature and extent.

Grey scale ultrasonography coupled with color Doppler flow imaging has the advantage of providing rapid, relative, inexpensive, and non-invasive assessment of lesion morphology and 


\section{CASE REPORT}

vascular components. Pulsed Doppler ultrasound permits spectral analysis of arterial and venous flow and measurement of flow velocity.

Harriet J. Paltiel, et. al (4) used grey scale, color Doppler and spectral Doppler to localize previously untreated vascular anomalies and to differentiate haemangioma from vascular malformations.

The need for diagnostic imaging usually arises when a lesion is atypical in appearance or presentation or when it is located deep within the subcutaneous tissues and is therefore difficult to assess by means of physical examination. $(5,6-11)$

Surprisingly little has been written regarding the role of US in the diagnosis of vascular anomalies, despite its wide availability, ease of use, non-invasiveness, and relatively low cost

To our knowledge, no prior publication has attempted to characterize the differential US imaging features of the various soft-tissue vascular anomalies, and also no prior publications were found where ultrasound imaging was used intraoperatively to locate the feeding vessels and help in ligation of the same with minimal dissection, thereby avoiding excess bleeding and injury to nearby vital structures.

Latifi HR, Siegel MJ told that they made no attempt to assess the reliability of gray-scale US and color Doppler flow imaging in distinguishing vascular anomalies from other soft-tissue masses. There is an overlap of imaging features between vascular anomalies and other soft-tissue lesions, both benign and malignant. (10)

Due to increase in usage of ultrasound to give nerve blocks, anesthesiologists are gaining expertise in sonoanatomy and can easily locate structures like nerves and vessels, and can do color flow mapping and Doppler studies. This art of anesthesiologist can be an invaluable help the surgeons intraoperative.

CONCLUSION: This case illustrates the invaluable contribution that ultrasound has made to modern, regional anesthetic practice. In addition, it has made a very difficult and complex surgery into a very simple and easy one, and also resulted in a successful outcome.

\section{REFERENCES:}

1. Finn MC, Glowacki J, Mulliken JB. Congenital vascular lesions: clinical application of a new classification. J Pediatr Surg 1983; 18: 894-899.

2. Mulliken JB, Glowacki J. Hemangiomas and vascular malformations in infants and children: a classification based on endothelial characteristics. Plast Reconstr Surg 1982; 69: 412-422.

3. Enjolras O, Mulliken JB. The current management of vascular birthmarks. Pediatr Dermatol 1993; 10: 311-313.

4. Harriet J Paltiel, Patricia E Burrows, Harry P W Kozakewich, David Zurakowski, John B Mulliken. Soft Tissue Vascular Anomalies: Utility of US for Diagnosi. Radiology, March 2000, 214: 747754.

5. Dubois J, Patriquin HB, Garel L, et al. Soft-tissue hemangiomas in infants and children: diagnosis using Doppler sonography.AJR Am J Roentgenol 1998; 171: 247-252.

6. Burrows PE, Laor T, Paltiel H, Robertson RL. Diagnostic imaging in the evaluation of vascular birthmarks. Dermatol Clin 1998; 16: 455-488.

7. Yoshida H, Yusa H, Ueno EI. Use of Doppler color flow imaging for differential diagnosis of vascular malformations: a preliminary report. J Oral Maxillofac Surg 1995; 53: 369-374. 


\section{CASE REPORT}

8. Howlett DC, Roebuck DJ, Frazer CK, Ayers B. The use of ultrasound in the venous assessment of lower limb Klippel-Trenaunay syndrome. Eur J Radiol 1994; 18: 224-226.

9. Bulas DI, Johnson D, Allen JF, Kapur S. Fetal hemangioma: sonographic and colour flow Doppler findings. J Ultrasound Med 1992; 11: 499-501.

10. Latifi HR, Siegel MJ. Colour Doppler flow imaging of paediatric soft tissue masses. J Ultrasound Med 1994; 13: 165-169.

11. Dubois J, Garel L, Grignon A, et al. Imaging of hemangiomas and vascular malformations in children. Acad Radiol 1998; 5: 390-400.

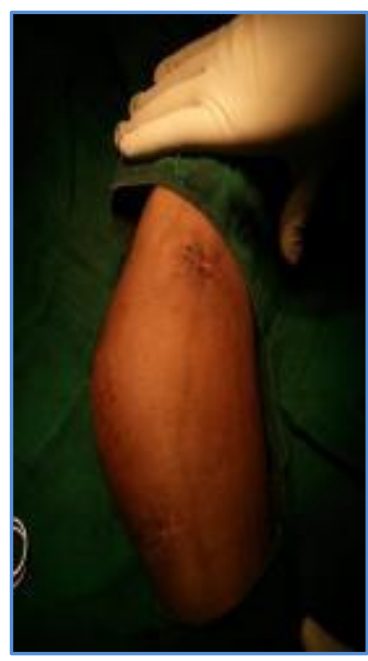

Fig 1: Vascular Tumor in the Forearm

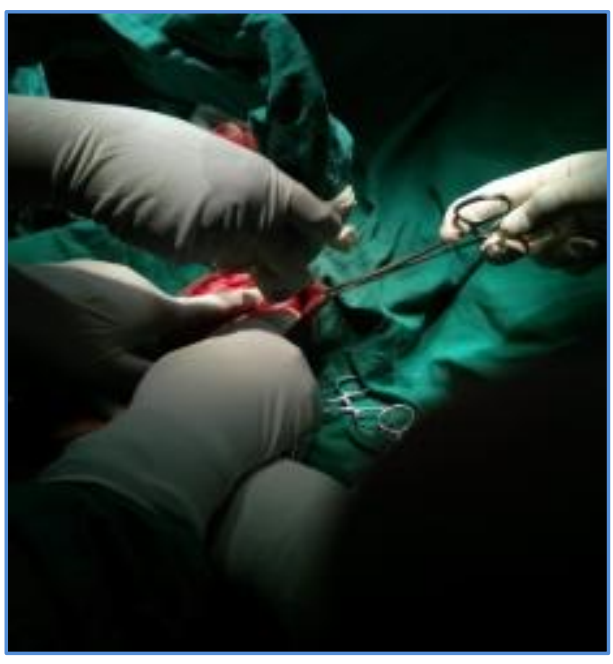

Fig 2: USG Probe Wrapped in Sterile Glove and Drape

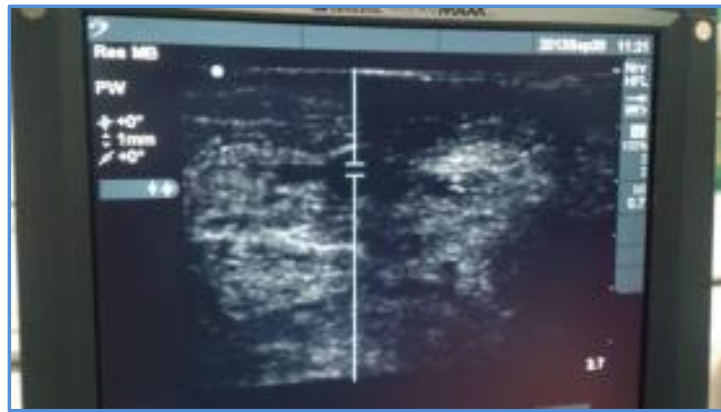

Fig 3: Feeding Vessels Confirmed with Colour Flow and Doppler

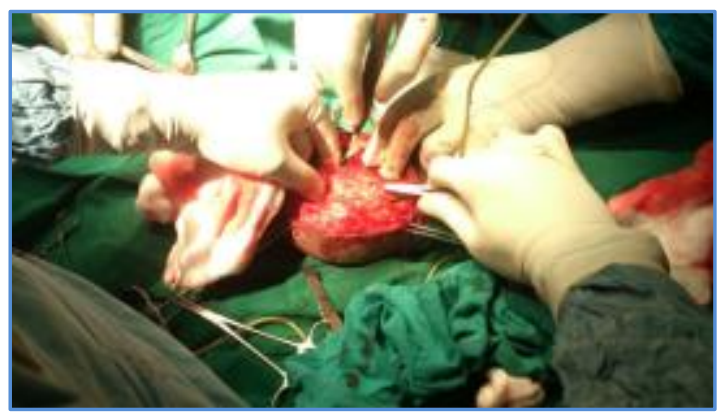

Fig 4: Ligation of Feeding Vessel 


\section{CASE REPORT}

\section{AUTHORS:}

1. Gajendra Singh

2. Pratima B. Patil

\section{PARTICULARS OF CONTRIBUTORS:}

1. Associate Professor, Department of Anaesthesiology, M. R. Medical College, Gulbarga.

2. Assistant Professor, Department of Anaesthesiology, M. R. Medical College, Gulbarga.

\section{NAME ADDRESS EMAIL ID OF THE CORRESPONDING AUTHOR:}

Dr. Gajendra Singh, \# 170, K. H. B. Colony,

M. S. K. Mill Road,

Shanti Nagar, Gulbarga-585103,

Karnataka, India.

Email: gajendra.glb@gmail.com

Date of Submission: 14/11/2014. Date of Peer Review: 15/11/2014. Date of Acceptance: 24/11/2014. Date of Publishing: 27/11/2014. 